\title{
A PROSPECTIVE STUDY ON ANTIMICROBIAL UTILIZATION PATTERN IN OUTPATIENT DEPARTMENT AT TERTIARY CARE HOSPITAL, PUNE, INDIA
}

\author{
SARANG A DESHMUKH ${ }^{1 *}$, YASHASVI AGARWAL ${ }^{2}$, HARSHITAHIRAN ${ }^{2}$, UMA BHOSALE ${ }^{1}$ \\ ${ }^{1}$ Department of Pharmacology, SMT Kashibai Navale Medical College and General Hospital, Pune, India. ${ }^{2} I^{\text {nd }}$ year MBBS students, SMT \\ Kashibai Navale Medical College and General Hospital, Pune, India. Email: drsarang2000@yahoo.com
}

Received: 14 December 2017, Revised and Accepted: 22 January 2017

\section{ABSTRACT}

Objective: The objective of the study was to evaluate antimicrobial prescription pattern in outpatient departments.

Method: This was a prospective, cross-sectional and observational study over 12 weeks total 400 prescriptions of either gender and age; containing antimicrobial agents (AMAs) were analyzed for demographic data and the WHO prescribing indicators.

Results: Most of prescription were given to men ( $\mathrm{n}=262)$. The most common group of AMA used was Cephalosporins ( $\mathrm{n}=141,35.25 \%)$; of which Ceftriaxone was most commonly prescribed ( $\mathrm{n}=73,18.25 \%)$. 10 AMAs were from the WHO essential medicine list AMAs. Men outnumbered women in prescribing antibiotics ( $\mathrm{n}=262$ vs. 138). Most of AMAs receivers were between 26 and 35 years $(\mathrm{n}=128,32 \%)$. Amoxicillin+Clavulanic acid fixeddose combination was most common $(n=84,21 \%)$. Most of the prescriptions were containing four drugs per prescriptions $(n=130,32.5 \%)$. Only $10 \%$ of the prescription was given by generic name and rest $90 \%$ were given by brand name. Oral dosage form of AMAs was predominant ( $\mathrm{n}=340,85 \%$ ). Vitamins and supplement were most common comedication received by patients.

Conclusion: Antibiotic use was found to be reasonable and rational in most of the cases. However, still, prescribers should improve prescribing practices and make it more rational.

Keywords: Antimicrobials, Prescribing pattern, WHO prescribing indicators, Rational use of drugs, Outdoor patients.

(c) 2018 The Authors. Published by Innovare Academic Sciences Pvt Ltd. This is an open access article under the CC BY license (http://creativecommons. org/licenses/by/4. 0/) DOI: http://dx.doi.org/10.22159/ajpcr.2018.v11i5.24266

\section{INTRODUCTION}

Drug utilization studies assess the appropriateness of pharmacotherapy with important implications for clinical practice as they provide a clear picture of real world use pattern and allow identifying areas that need change and improvement. It also provides insight into efficacy of drugs [1]. Many drug utilization studies have shown considerable variations in prescribing practices with a high rate of polypharmacy, which is generally used when there is a failure to control symptoms.

For proper antimicrobial agents (AMAs) prescribing, the clinician should try to define the type of infection and the presumable causative microorganism. The points to be evaluated for AMA prescribing are justifications of the prescription, more effective alternatives, less toxic alternatives, less expensive alternatives and drugs with narrower spectrum. That is why clinicians should be evaluated by the ongoing prescription audit. Prospective drug utilization study can have an immediate and direct effect on patient care by detecting problems before a prescription is dispensed [2].

Therefore, the present study was conducted to understand and evaluate the prescription pattern of AMAs at SMT Kashibai Navale Medical College and Hospital, Pune, India.

\section{METHODS}

This was a prospective, cross-sectional and observational study over 12 weeks, conducted in clinical Outpatient Departments of SMT Kashibai Navale Medical College and Hospital, Pune, India. Out of 500 prescriptions scrutinized, 400 prescriptions containing AMAs were selected. Prescriptions given to either gender, for any age, and any clinical diagnosis were included. Prescriptions not containing AMAs were excluded. Prescriptions are analyzed using the WHO prescribing indicators, also for fixed-dose combinations (FDCs) used and comedications prescribed.

The protocol for the study was submitted to the Institutional Ethics Committee, and the study was started after approval (Ref.SKNMC/ Ethics/App/2016/144). Data were calculated using Microsoft Excel and expressed in percentage.

\section{RESULTS AND OBSERVATIONS}

Out of 500 outdoor prescriptions, 400 prescriptions were containing AMAs. Men outnumbered women in prescribing antibiotics ( $n=262$ vs 138) (Fig. 1). Most of AMAs receivers were from age 26 to 35 years $(\mathrm{n}=128,32 \%)$ followed by $15-25$ years $(\mathrm{n}=82,20.5 \%)$ (Fig. 2). The most common group of AMA used was cephalosporins ( $n=141$, $35.25 \%)$; in that ceftriaxone was most commonly prescribed $(n=73$, $18.25 \%)$, followed by penicillins ( $n=92,23 \%)$; in this amoxicillin $(n=76$, $19 \%$ ) was most common. Third most common group was macrolide and azithromycin ( $\mathrm{n}=72,18 \%)$ was most common. Out of 16 different types of AMAs, 10 were from the WHO essential medicine list, but that comprise about $88.5 \%$ of all AMAs. FDCs are routinely used here, amoxicillin+clavulanic acid FDC was most common $(n=84,21 \%)$. We also tried to find out overall polypharmacy frequency. We found most of the prescriptions were containing four drugs per prescriptions $(\mathrm{n}=130,32.5 \%)$ and 91 prescriptions were containing three drugs per prescriptions ( $\mathrm{n}=91,22.75 \%)$. Only $10 \%$ of the prescription was given by generic name and rest $90 \%$ were given by brand name. We also found that oral dosage form of AMAs was predominant $(n=340$, $85 \%)$ (Table 1). Patients also got a different kind of comedications, in those, vitamin and supplement were common $(n=275,68.75 \%)$ (Table 2 ). AMA use was found to be rational in $80 \%$ of patients. Most of the prescriptions were containing comedications. 
Table 1: Gender wise distribution of parameters

\begin{tabular}{|c|c|c|c|}
\hline Category & Men & Women & total $(\%)$ \\
\hline \multicolumn{4}{|l|}{ Individual Drugs } \\
\hline Amoxicillin & 44 & 32 & $44(11)$ \\
\hline Azithromycin & 55 & 17 & $55(13.75)$ \\
\hline Cefadroxil & 0 & 20 & $0(0)$ \\
\hline Cefixime & 23 & 16 & $23(5.75)$ \\
\hline Cefpodoxime & 5 & 0 & $5(1.25)$ \\
\hline Ceftriaxone & 50 & 23 & $50(12.5)$ \\
\hline Cefuroxime & 4 & 0 & $4(1)$ \\
\hline Ciprofloxacin & 31 & 11 & $31(7.75)$ \\
\hline Clavulanic acid & & & $0(0)$ \\
\hline Clindamycin & 5 & 0 & $5(1.25)$ \\
\hline Doxycycline & 31 & 4 & $31(7.75)$ \\
\hline Penicillin G & 4 & 0 & $4(1)$ \\
\hline Piperacillin & 12 & 0 & $12(3)$ \\
\hline Nitrofurantoin & 4 & 23 & $4(1)$ \\
\hline Norfloxacin & 2 & 5 & $2(0.5)$ \\
\hline Ofloxacin & 24 & 0 & $24(6)$ \\
\hline \multicolumn{4}{|l|}{ FDCs } \\
\hline Amoxicillin+Clavulanic acid & 48 & 36 & $84(21)$ \\
\hline Piperacillin+Tazobactam & 12 & 0 & $12(3)$ \\
\hline Ciprofloxacin+Tinidazole & 30 & 23 & $53(13.25)$ \\
\hline \multicolumn{4}{|l|}{ Number of drugs/prescriptions } \\
\hline 1 & 4 & 10 & $4(1)$ \\
\hline 2 & 48 & 3 & $48(12)$ \\
\hline 3 & 65 & 26 & $65(16.25)$ \\
\hline 4 & 90 & 40 & $90(22.5)$ \\
\hline 5 & 20 & 13 & $20(5)$ \\
\hline 6 & 14 & 13 & $14(3.5)$ \\
\hline \multicolumn{4}{|l|}{ Route of administration } \\
\hline Oral & 340 & 240 & $100(85)$ \\
\hline Parenteral & 60 & 35 & $25(15)$ \\
\hline
\end{tabular}

Table 2: Comedications used with AMAs

\begin{tabular}{ll}
\hline Comedications & Number of prescriptions \\
\hline Vitamins and supplements & 275 \\
Pantoprazole & 160 \\
Paracetamol & 151 \\
Amlodipine & 87 \\
Aspirin & 76 \\
Propranolol & 65 \\
Metformin & 60 \\
Cetirizine & 55 \\
\hline
\end{tabular}

AMAs: Antimicrobial agents

\section{DISCUSSION}

Drug utilization is a tool to measure ongoing prescription practices. It has a direct impact on patients health care cost and health suffering. Today, antibiotics are one of the most expensive drug expenditure in hospitals accounting for $20 \%-50 \%$ of total pharmacy [3]. AMAs are most used and misused drugs by patients and prescribers [4]. The fear of physician whether he is missing any occult infection also makes him to use an antibiotic umbrella for protecting him and his patient. To get breakthrough from the irrational pattern of prescribing behavior of antibiotic, this study is done.

In our study, men received more antimicrobial prescriptions than women. Pallavi et al., Randad et al., and Gowthami et al. found the same result in their study [5-7]. Some studies found exactly opposite results [8]. The most common drug group prescribed was Beta-lactam antibiotics; in that most common AMA was ceftriaxone (18.25\%). Betalactams are commonly used AMA and use abundantly in practice. There are many studies who found same result $[4,7,9-13]$. Beta-lactams are well established AMAs regarding their efficacy and safety that may lead

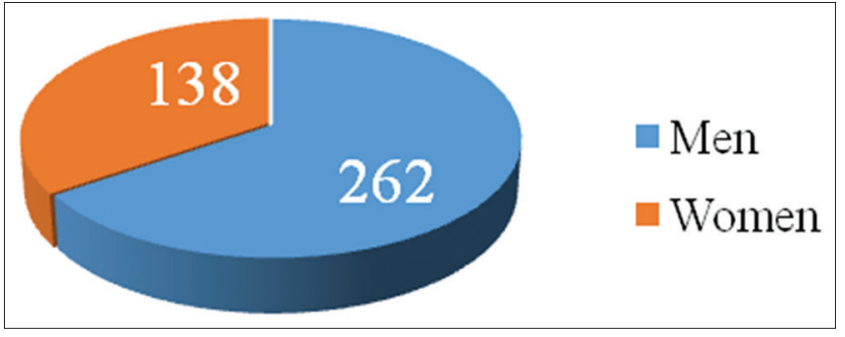

Fig. 1: Total number of prescriptions

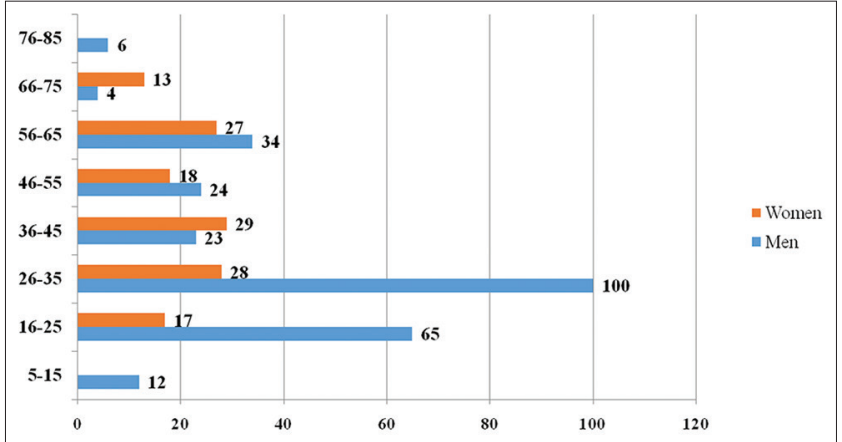

Fig. 2: Number of prescriptions as per age groups. $\mathrm{X}$-axis - number of prescriptions, Y-axis - age groups

to its widespread use. Pallavi et al. found broad-spectrum antibiotic was most common in their study [5]. Choice of AMA may differ from doctor to doctor, but ideally one should stick to ideal prescribing according to hospital formulary. Out of 16 AMAs, only 10 were from the WHO essential medicine list. Ramesh A et al. found same result [4]. FDCs are routinely used in practice. Amoxicillin plus Clavulanic acid combination was most common $(n=84,21 \%)$. This finding is in line with a study conducted by Gedam et al.[14]. Most of the patients were between 26 and 35 years age group, most of the prescriptions were for men $(n=100)$. Polypharmacy is a common phenomenon in practice, having a negative impact on patients. In our study, four drugs per prescription were most common pattern we found. This finding was with Randad et al. and Pallavi et al. [5,6]. 90\% of the prescriptions were given by brand names. Such habits lead to specific brand promotions. This finding coincides with Meher et al., Beg et al., and Pandiamunian et al. $[12,15,16], 85 \%$ of AMAs given by oral route of administration. This is because we included patients from the outpatient department. In studies conducted by Ramesh et al., Mahajan et al., Beg et al., Padiamunian et al., and Rasheeduddin et al. found opposite result, injectable AMAs were predominant $[4,11,12,16,17]$.

\section{CONCLUSION}

This study was purely based on outpatient department patients. Antibiotic use was found to be reasonable and rational in most of the cases. However, still, prescribers should improve prescribing practices make it more rational. There should be a strict check on polypharmacy. Prescribers should be motivated to prescribe from the WHO essential drug list. Prescribers should prescribe the drugs by their generic names. It can reduce prescribing and dispensing errors.

\section{ACKNOWLEDGMENT}

Authors are grateful to all clinical departments and Department of Pharmacology, SMT Kashibai Navale Medical College, Pune, India, for their contribution.

\section{CONFLICTS OF INTEREST}

There is no conflict of interest. 


\section{AUTHORS CONTRIBUTION}

Dr. Sarang Deshmukh has contributed in the initiation of concept; design this study, literature search, data acquisition, data analysis. Miss Yashashri and Miss Harshita have contributed in statistical analysis and manuscript preparation. Dr. Uma Bhosale has done manuscript editing and review.

\section{REFERENCES}

1. WHO. Introduction to Drug Utilization Research. Geneva, Switzerland: WHO; 2003. p. 6-11. Available from: http://www.who.int/medicines/ areas/quality_safety/safety_efficacy/Drug\%20utilization\%20research. pdf. [Last accessed on 2017 Dec 10].

2. Prajapati V, Bhatt JD. Study of prescribing patterns of antimicrobial agents in the paediatric wards at tertiary teaching care hospital, Gujarat. Int J Pharm Sci Res 2012;3:2348-55.

3. Jayakar B, Aleykutty NA, Mathews SM. Evaluation of oral antibiotic utilization in medical in patients. Int J Pharm Pharm Sci 1992;4:304-5.

4. Ramesh A, Salim S, Gayathri M, Nair U, Retnavally KG. Antibiotics prescribing pattern in the in-patient departments of a tertiary care hospital. Arch Pharm Pract 2013;4:71-6.

5. Pallavi PS, Tejasree B, Krishnakanth PV. Study of prescription patterns of antibiotics in tertiary care hospital. Int J Biomed Res 2016;7:372-4.

6. Randad RD, Bhagwate ST, Inamdar MK. Drug utilization study of some antibiotic in indoor setting at tertiary care teaching hospital in Central India: A descriptive study. Int J Basic Clin Pharmacol 2017;6:1123-6.

7. Gowthami B, Spurthi T, Afreen SS. Drug utilization evaluation of antibiotics in general medicine department of a tertiary care hospital. Int J Pharm Pharm Sci 2016;8:302-4.

8. Naik HG, Khanwelkar CC, Kolur A, Desai R, Gidamudi S. Drug utilization study on antibiotics use in lower respiratory tract infection.
Natl J Med Res 2013;3:324-7.

9. Forough AS, Hosseini SR, Jabbari S. Antibiotic utilization evaluation of inpatient and outpatient prescriptions in a rural general hospital in Iran. Int J Basic Clin Pharmacol 2015;4:531-6.

10. Khan FA, Singh VK, Sharma S, Singh P. A prospective study on the antimicrobial usage in the medicine department of a tertiary care teaching hospital. J Clin Diagn Res 2013;7:1343-6.

11. Rasheeduddi M, Shankar BR, Babu NJ, Reddy NL. Antibiotic utilization study in the department of surgery of a teaching hospital and research Centre. Sch J Appl Med Sci 2016;4:2918-23.

12. Beg MA, Bawa S, Dutta S, Anjoom M, Vishal S. Study of antimicrobial prescribing pattern in a tertiary care teaching hospital at Dehradun, Uttarakhand, India-A tool to teach clinical pharmacology to MBBS students. Int J Basic Clin Pharmacol 2016;5:2444-8.

13. Anand N, Nagendra Nayak IM, Advaitha MV, Thaikattil NJ, Kantanavar KA, Anand S, et al. Antimicrobial agents' utilization and cost pattern in an intensive care unit of a teaching hospital in south India. Indian J Crit Care Med 2016;20:274-9.

14. Gedam S, Singh AP, Barmaiya N. Prescribing pattern of antimicrobial agents in intensive care unit of a teaching hospital in Central India. Int J Basic Clin Pharmacol 2017;6:1507-10.

15. Meher BR, Mukharjee D, Udayshankar. A study on antibiotic utilization pattern in a general medicine ward of a tertiary care teaching hospital. J Chem Pharm Res 2014;6:1847-9.

16. Pandiamunian J, Somasundaram G. A study on prescribing pattern of antimicrobial agents in the medical intensive care unit of a tertiary care teaching hospital in Puducherry union territory, South India. Int J Pharm Pharm Sci 2014;6:235-8.

17. Mahajan B, Kaushal S, Chopra S. Drug utilization study of antimicrobial agents (AMAs) in the intensive care units (ICUs) at medical college hospital of North India. JK Sci J Med Educ Res 2013;15:129-32. 